\title{
O CINEMA NAS CRÔNICAS MÉDICAS DE MOACYR SCLIAR
}

\section{Cinema in MOACYR SCliaR's MEDICAL CHRONICLES}

\author{
Lemuel de Faria Diniz" \\ Márcia Gomes Marques**
}

Resumo: A atenção neste artigo recai sobre um nicho expressivo da literatura de Moacyr Scliar - as crônicas. Expandindo a proposta de que o escritor fez uso de suas vivências para compor suas obras, destaca-se que as mídias, e entre elas o cinema, são alvo da atenção do escritor, despontam como tema em suas crônicas e nelas aparecem como intertexto e referência intermidiática. Identifica-se que, desde o início de sua produção literária, sua atuação como cronista está marcada pela lógica da imprensa, com publicações em jornais e em livros. Após mapear as fases atribuídas a sua literatura, verifica-se a associação temática entre medicina e cinema em suas crônicas, nas quais o cinema e as obras fílmicas aparecem como recurso composicional, como motivo ou ambientação, para exemplificar questões complexas ou ilustrar de modo concreto reflexões.

Palavras-chave: Crônica; Medicina; Cinema.

Aвstract: The attention in this article falls on an expressive niche of Moacyr Scliar's literature - the chronicles. Expanding the proposal that the writer made use of his experiences to compose his works, it is highlighted that the media, and among them cinema, are the target of the writer's attention, they appear as a theme in his chronicles and appear in them as an intertext and intermidiatic reference. It is identified that his performance as a chronicler is marked by the logic of the press, with publications in newspapers and books. After mapping the phases attributed to his literature, there is a thematic association between medicine and cinema in his chronicles, in which cinema and film works appear as a compositional resource, as a motive or setting, to exemplify complex issues or to illustrate reflections in a concrete way.

KEYwords: Chronicles; Medicine; Cinema.

\footnotetext{
"Professor do Curso de Letras da Universidade Federal de Mato Grosso do Sul (UFMS), Câmpus de Coxim. Doutor em Letras pela Universidade Presbiteriana Mackenzie. Pós-doutorando em Estudos de Linguagens, Área de concentração: Literatura, Estudos Comparados, Interartes (UFMS).E-mail: prlemuel@hotmail.com.

"* Doutora em Scienze Sociali pela Pontificia Università Gregoriana (Itália) e Professora Titular da Universidade Federal de Mato Grosso do Sul (UFMS). Líder do grupo de pesquisa Mídia e Mediações Comunicativas da Cultura (CNPq). E-mail: marciagm@yahoo.com.
} 


\section{INTRODUÇÃo}

No conjunto da produção literária do escritor Moacyr Scliar (1937-2011) figuram mais de setenta livros de gêneros diferenciados, tais como romances, ensaios, crônicas, ficções infanto-juvenis e contos. O escritor gaúcho teve suas obras publicadas em mais de vinte países e foi reconhecido quatro vezes com o "Prêmio Jabuti", pelas obras: O olho enigmático (1986), categoria Contos; Sonhos tropicais (1992), categoria Romance; A mulher que escreveu a Bíblia (1999), categoria Romance; e Manual da paixão solitária (2008), categoria Romance, também escolhida obra de Ficção do Ano. O escritor colaborou por décadas como cronista em vários órgãos da imprensa no país, como a Folha de São Paulo e o Jornal Zero Hora (RS), e foi membro da Academia Brasileira de Letras a partir de 2003.

Na primeira etapa de sua carreira literária, Scliar elabora obras que tematizam a cidade de Porto Alegre e o Estado do Rio Grande do Sul. Isso foi pontuado por Regina Zilberman (2009), que dá o nome a essa fase de suas publicações, entre 1972 e 1977, de "os romances de Porto Alegre", entre os quais se destacam Os mistérios de Porto Alegre (cujo título alude a Os mistérios de Paris, de Eugene Sue, e a Mistérios de Lisboa, de Castelo Branco), livro constituído de contos e crônicas, de 1975, e O ciclo das águas, de 1977, reconhecido com o segundo lugar no Prêmio Érico Veríssimo de Romance. O segundo período dessa cronologia literária atribuída à sua obra dá-se pelo predomínio temático na interface judaísmo-Brasil, abarcando obras como O centauro no jardim (1980), A estranha nação de Rafael Mendes (1983) e Cenas da vida minúscula (1991), publicadas entre 1980 e 1991. O terceiro período abrange A mulher que escreveu a Bíblia (1999), Os vendilhões do Templo (2006) e Manual da paixão solitária (2008), e se caracteriza por "privilegiar personagens sugeridas pela leitura da Bíblia hebraica" (Ibidem, p. 116).

Na sua maneira de produzir, muitas vezes num só ano o autor publica obras de gêneros diferenciados. Isso se nota em 1984, ano em que, além do livro de crônicas A massagista japonesa, Scliar lança literatura infanto-juvenil (Memórias de um aprendiz de escritor) e as antologias Dez contos escolhidos e Os melhores contos de Moacyr Scliar. Em 1995 e em 2001, o mesmo fenômeno é percebido: no primeiro, foram editadas as crônicas do Dicionário do viajante insólito e os infanto-juvenis Um sonho do caroço do abacate e Introdução à prática amorosa; em 2001, verifica-se a publicação das crônicas de $O$ imaginário cotidiano junto ao infanto-juvenil Ataque do comando $P$. Q. Nota-se, também nos casos assinalados, que a atuação do Scliar cronista ocorre de forma contínua e paralela à publicação de obras nos demais gêneros literários.

Com relação às crônicas, ele as escreveu por aproximadamente quarenta anos: publicou as primeiras no início dos anos 1970. Dos diversos gêneros a que se debruçou, a crônica de jornal esteve presente em sua trajetória do começo ao final, sendo, inclusive, "os últimos textos que o autor legou a seus leitores" (ZILBERMAN, 2012, p. 9), no início de 2011. A atenção neste artigo recai justamente sobre esse nicho da produção do escritor, as crônicas, e entre elas as crônicas médicas, no que poderia entender-se como manifestação de sua experiência 
de vida em sua literatura, visto que Scliar formou-se em medicina, em 1962, e doutorou-se em Saúde Pública com a tese Da Bíblia à psicanálise: saúde, doença e medicina na cultura judaica. Com relação à repercussão da atuação na medicina em sua literatura, pode-se considerar que tenha dado os primeiros passos de seu percurso literário ainda em tempos de faculdade, visto que, na seção "Sobre o autor" do livro Dicionário do viajante insólito, lê-se que "ao ingressar na faculdade de medicina, [Scliar] começou a escrever para o jornal Bisturi” (SCLIAR, 2011, p. 133).

Do universo de suas crônicas, selecionam-se aquelas com temas ligados à medicina, a partir das quais se analisa a recorrência da menção ao cinema nessa parte da produção do autor. Expandindo a recorrente proposta de que o escritor fez uso de suas vivências (SZKLO, 1990; WALDMAN, 2003; ZILBERMAN, 2009) e de assuntos de interesse para compor suas obras - a cidade e o bairro onde cresceu, o judaísmo, a imigração, a atuação como médico e a formação em saúde pública - destaca-se que, como aspecto importante na segunda metade do século XX no país, as mídias, e entre elas o cinema, são alvo da atenção do escritor, aparecendo nas crônicas médicas como recurso composicional, no intertexto estabelecido com obras fílmicas (GOMES, 2009) e como referência intermidiática (RAJEWSKY, 2012).

Identifica-se que o escritor recorre ao cinema como motivo e recurso composicional e de ambientação, tomando-o como parte da paisagem cultural da cidade e da sociedade de seu tempo, como algo a ser considerado como parte da cena e da vida de todos os dias com a qual tece suas crônicas. A sua proximidade das mídias eletrônicas e da cultura popular e midiática se manifesta, também, no fato de escrever para jornal, ademais de trazer o cinema como motivo em sua obra.

Propõe-se, adicionalmente, que Scliar se vale da crença, compartilhada por Julio Cabrera, de que o cinema apresenta uma linguagem propícia para expressar as intuições filosóficas concernentes aos "limites de uma racionalidade unicamente lógica e a respeito da apreensão de certos aspectos do mundo que não parecem ser captados por uma total exclusão do elemento afetivo" (CABRERA, 2006, p. 18). Para Cabrera, o uso do cinema é estratégico: "trata-se de uma caracterização conveniente do cinema para propósitos filosóficos, isto é, para a intenção de considerar os filmes como formas de pensamento" (Ibidem, p. 19). De modo análogo, Scliar evoca o cinema como estratégia de desenvolvimento de reflexões em formato crônica e voltadas ao público que o acompanha nos jornais.

Quanto à combinação de elementos temáticos, ou seja, do que se manifesta em sua obra como seleção (incluir e excluir) e hierarquia (no sentido de ser mais ou menos central na composição) de certos elementos da realidade e da experiência social, interessa explorar se a vivência do escritor como médico se expressa em sua obra, e sobre a intersecção que estabelece dos temas ligados à saúde com a menção ao cinema. Observa-se que Scliar valeu-se de seus conhecimentos médicos como material para as suas criações literárias, o que se verifica, por 
exemplo, no fato de o escritor gaúcho ser autor de 21 obras com temática médica. ${ }^{1}$ Por essa trajetória, diz-se que Scliar está inscrito numa linhagem de médicos-escritores, como Pedro Nava (1903-1984) e Guimarães Rosa (1908-1967). No que tange especificamente às crônicas, essa temática aparece esparsa em seus livros, é tema central de três dessas publicações, assim como esteve regularmente presente nas que publicou exclusivamente em jornal.

\section{A crônica e o cronista Moacyr Scliar}

No ensaio Cronista e leitor, Zilberman afirma que a crônica é um gênero de difícil demarcação, pois pode tratar de fatos contemporâneos, narrar tanto histórias verídicas como imaginárias, relembrar pessoas e acontecimentos, realizar comentários sobre literatura ou outras expressões culturais. Por sua lógica de produção e de consumo, a crônica, assim como o folhetim, é constitutivamente um gênero poroso à atualidade (MARTÍN BARBERO, 1987), ou tem porosidade de assuntos, segundo Granja (2015). A sua primeira acepção, explica Fischer (2004), derivava do latim chronica - relato, história escrita ou narrativa de fatos dispostos em ordem cronológica -, mas o termo migrou desde o domínio do relato histórico para o literário, e logo depois passou a ser utilizado na literatura em um gênero específico ligado ao jornalismo.

Dentre os escritores das crônicas modernas está Moacyr Scliar, considerado um dos maiores cronistas brasileiros, escrevia regularmente em jornais de circulação regional e nacional. O escritor foi um defensor da crônica na literatura brasileira, considerando-a um gênero literário importante; seu uso, contudo, era mais ou menos imediato, diferente da ficção (romance), gênero no qual uma boa ideia pode ficar amadurecendo por anos (FISCHER, 2004, p. 7-17). Parte de suas crônicas foram inspiradas em matérias de jornais. Em seu processo de criação, dizia precisar de um elemento desencadeante e, nesse processo, a notícia de jornal cumpria esse papel, dizia Scliar:

[...] pode ser um episódio histórico, uma pessoa que conheci, uma história que me contaram, uma notícia de jornal.... Daí em diante é uma incógnita. Sou muito rápido escrevendo para jornal, mas quando se trata de uma ficção mais longa é diferente; aí períodos de rapidez se alternam com outros de muita lentidão, resultante de dúvidas que vão desde a questão do foco narrativo até a incerteza quanto à validade do projeto [...] (ZILBERMAN, 2009, p. 118).

\footnotetext{
${ }^{1}$ As obras com temática médica são as seguintes, divididas por gêneros. Contos: Histórias de um médico em formação. Romances: Doutor Miragem; Sonhos tropicais; A majestade do Xingu. Literatura infantojuvenil: O livro da medicina; Aprendendo a amare a curar; Respirando liberdade. Crônicas: O olhar médico: crônicas de medicina e saúde; A face oculta: inusitadas e reveladoras histórias da medicina; e Território da emoção: crônicas de medicina e saúde, este organizado por Regina Zilberman. Ensaios: Um olhar sobre a saúde pública; Do mágico ao social: a trajetória da saúde pública; Cenas médicas; Oswaldo Cruz: cadeira 5, ocupante 2; A paixão transformada: história da medicina na literatura; Meu filho, o doutor: medicina e judaísmo na história, na literatura e no humor; A linguagem médica; Oswaldo Cruz \& Carlos Chagas: o nascimento da ciência no Brasil; Saturno nos trópicos: a melancolia européia chega ao Brasil; Saúde pública: histórias, políticas e revolta; Rubem Alves \& Moacyr Scliar conversam sobre o corpo e a alma.
} 
O trecho é referente a uma entrevista concedida pelo escritor em 2009, quando há décadas escrevia e publicava em jornais. Também em sua autobiografia, intitulada $O$ texto, ou: a vida: uma trajetória literária, fala sobre seu processo de criação e sobre as diferentes rotinas criativas relativas à elaboração (i) de crônicas para serem publicadas por jornais e (ii) de romances, concebidos para serem lidos em livros.

É uma experiência no mínimo curiosa passar da página do livro para a página do jornal. Sim, em ambos os casos trata-se de texto impresso, destinado a um público, mas as diferenças são grandes, e históricas. [...] Os escritores escreviam para a eternidade; os jornalistas estavam presos aos assuntos do momento, nem sempre agradáveis. [...] Os escritores podiam fazer pesquisas formais, mesmo que estas resultassem em textos obscuros; os jornalistas tinham, e têm, a obrigação da clareza. (SCLIAR, 2007a, p. 237-238).

O fragmento acima dialoga com parte do que Scliar menciona na entrevista intitulada Falar com Deus? Só se for com ligação a cobrar, na qual esclarece que não se considera jornalista, mas sim um colaborador de jornal que abomina ouvir gente que deprecia o jornalismo. Ele afirma: "[...] o meu convívio com o jornalismo foi contínuo. Aprendi, em primeiro lugar, a fazer um texto enxuto. Aprendi a ir direto ao ponto, entregar o texto na hora", além de precisar escrever "com muita antecedência por causa dos problemas de ilustração". Relacionando essas considerações à explanação acerca do embate entre o livro e o jornal, Scliar pondera que no país "surgiu um gênero que se tornou o elo de ligação entre literatura e o espaço jornalístico: a crônica". No jornal, a crônica é "um respiradouro, uma brecha na massa não raro sufocante de notícias" (SCLIAR, 2007a, p. 239).

Este trabalho vale-se do depoimento de Scliar não como intento de, como afirma Iser (2013) em O fictício e o imaginário, indagar sobre a psique do autor para desvendar suas intenções. Tal como sustenta Iser (2013, p. 37), entende-se que seja "provável que a intenção não se revele nem na psique nem na consciência, mas que possa ser abordada apenas através das qualidades de manifestação que se evidenciam na seletividade do texto face a seus sistemas contextuais". Aqui o testemunho de Scliar é entendido, de tal forma, como elemento transtextual, no sentido de Genette (2006), como forma estendida de paratextualidade ou metatextualidade, que acrescenta e desdobra aspectos de seus processos de criação, e repercute em sua fortuna crítica.

Em termos de publicações, a atuação de Scliar como cronista começa em 1984, ano em que é lançada a primeira edição de A massagista japonesa, seguida, em 1989, por Um país chamado infância. Em 1995, vem à lume as crônicas do Dicionário do viajante insólito, que recebeu o Prêmio Açorianos, e um ano depois chega às livrarias Minha mãe não dorme enquanto eu não chegar. Em 2001, edita O imaginário cotidiano, também laureado com o Prêmio Açorianos, e neste mesmo ano publica A língua de três pontas: crônicas e citações sobre a arte de falar mal e A face oculta: inusitadas e reveladoras histórias da medicina. Em 2004, trabalhando num projeto da Editora Global, Fischer 
seleciona textos para o livro Moacyr Scliar, expondo essa vertente do escritor para a Coleção Melhores Crônicas. Em 2005 lança O Olhar Médico, em 2009, Histórias que os jornais não contam. Com a morte do autor, em 2011, as publicações passam a ser póstumas, e Zilberman seleciona crônicas para as seguintes compilações: A poesia das coisas simples (2012) e Território da emoção: crônicas de medicina e saúde, A banda na garagem (2014) e A nossa frágil condição humana (2017). Desses, apenas Território da emoção, A face oculta e o Olhar médico reúnem crônicas médicas no todo, enquanto os livros de 2012 e de 2014 trazem algumas crônicas médicas esparsas entre textos de outro enfoque.

Por cerca de 40 anos, do início dos anos 70 a 2011, Moacyr Scliar publicou crônicas regularmente no jornal Zero Hora, do Rio Grande do Sul. Publicou nos cadernos Vida e Donna, na coluna A Cena Médica, mantendo uma coluna semanal no caderno de Notícias. Os temas, como sugerem as variadas editorias e suplementos onde publicava, eram diversos, abarcando desde questões de saúde, vida familiar, passando também por assuntos cotidianos da cidade e do estado, reservados principalmente à coluna das terças-feiras, na página 2 do jornal. Sobre sua participação para o Caderno Vida do Jornal Zero Hora, ele afirmou tratar-se de um trabalho importante, porque é uma forma de escrever sobre Medicina de maneira mais humanista. Já no jornal Folha de São Paulo, Scliar escreveu a partir de 1993, na seção Cotidiano, com crônicas inspiradas em notícias de jornais, sendo que algumas delas são crônicas médicas. Atuou como cronista, ainda, no Correio Braziliense, do Distrito Federal, de 2006 a 2011, escrevendo para o caderno Diversão e arte.

Examinando as crônicas de Scliar publicadas na Folha de São Paulo, Lealis Guimarães (1999, p. 161) toma como corpus de análise cinco crônicas e aponta que, nelas, "o humor é inerente à criação literária, manifestando-se através do procedimento paródico", que se combina, em seu efeito estético, à exploração de "assuntos insólitos, ou constrangedores, do cotidiano veiculado pela notícia, para promover efeitos tragicômicos". Com respeito à leitura, com suas crônicas passa-se "ao mundo do imaginário e, nesse transporte do real para o fictício, [...] que funciona como crítica às ordens e valores predeterminados". Do corpus analisado por Guimarães (1999), o único texto que se enquadra no perfil de crônica médica é Consultando no posto de saúde fantasma, elaborada a partir de uma notícia desanimadora sobre o sistema de saúde, na qual nota-se um "humor crítico diante do fato noticiado" (GUIMARÃES, 1999, p. 121-122).

O imaginário cotidiano, Moacyr Scliar (Coleção Melhores Crônicas), Histórias que os jornais não contam e A banda na garagem têm em comum reunirem crônicas inspiradas em notícias de jornal. Esses livros apresentam a seguinte disposição: logo após o título da crônica, é apresentada a notícia que serve de inspiração e, em seguida, vem o texto de Scliar. Algumas das crônicas desses livros apresentam temáticas relacionadas à Medicina, que são compostas de personagens em situações nas quais se reportam superficialmente aspectos da Medicina. Desses textos, pode-se mencionar "Ele (ex-ela) e ela (ex-ele)", cujo narrador cria uma história sobre as dificuldades de adaptação vivenciadas por um casal que muda de sexo. Esse texto 
integra Moacyr Scliar (2004, p. 215-216), "uma reunião de crônicas que o destacam no gênero com maior nitidez” (HANCIAU, 2012, p. 118). Sobre a pertinência de classificá-los como crônicas, os textos inspirados em manchetes de jornais, no entender de Zilberman (2012, p. 16), devem ser assim considerados, pois "crônicas são também narrativas de eventos efetivamente ocorridos ou imaginários". Para Scliar, porém, por serem ficcionais, esses textos não seriam crônicas. ${ }^{2}$ Em entrevista concedida a Fischer, o escritor comenta sobre os limites entre crônica e outros gêneros:

[...] acho, sim, que os limites da crônica são claros. Crônica não é conto: é um comentário sobre a realidade, portanto exclui ficção (ainda que, na Folha de São Paulo, eu escreva um texto ficcional baseado em notícias de jornal. Mas eu não o chamo de crônica. Nem de conto. É uma espécie de crônica ficcionalizada). Crônica não é um gênero tão erudito quanto o ensaio. Crônica não é tão factual quanto o artigo (sobre política, por exemplo). (SCLIAR apud FISCHER, 2011, p. 102).

O Dicionário do viajante insólito reúne uma coletânea de crônicas inspiradas em viagens de Scliar, e contém apenas um texto no qual há referência à medicina: G de Gueixa, cujo personagem sonha em se deitar com uma gueixa. Seu chefe o convida para uma viagem ao Japão e, em seu quarto de hotel, ele "solicita" uma gueixa. A visitante é velha e cega, ele tenta se desvencilhar dela e machuca a coluna, necessitando assim ceder aos cuidados da gueixa, que era, de fato, apenas massagista (SCLIAR, 2011, p. 35-38). Publicada em 1996, Minha mãe não dorme enquanto eu não chegar é outra obra que dispõe uma única crônica sobre saúde. Intitulada Pietá, que narra o sofrimento do escritor com a perda de sua mãe, acometida por um câncer, e de sua impotência, como médico, perante a situação (SCLIAR, 1996, p. 44-46).

Em A massagista japonesa, há textos que remetem a questões relacionadas à saúde. A narrativa que intitula o livro é, com ligeiras modificações, a mesma de "G de Gueixa", de o Dicionário do viajante insólito. Há outros textos nos quais são contadas histórias entremeadas de resquícios de conselhos médicos, como Ponte de safena, A um bebê com cólicas, Data certa, Decisão, O homem que corria (SCLIAR, 1984, p. 23-24, 53-54, 75-78, 107-109). A língua de três pontas: crônicas e citações sobre a arte de falar mal (2001) dispõe um capítulo intitulado Falando mal da medicina, no qual Scliar apresenta um histórico da evolução da medicina, seguido das citações que coligiu relacionadas à desconfiança nutrida por muitos sobre a atuação dos médicos (SCLIAR, 2001, p. 54-66).

\footnotetext{
${ }^{2}$ Em O texto, ou: a vida: uma trajetória literária, o escritor afirma: "Em 1993 fui convidado por um editor da Folha de S. Paulo para escrever um texto de ficção baseado em matérias publicadas no jornal. A proposta me surpreendeu. Achei até que tinha entendido mal: não se trataria de uma crônica? Não, não era crônica, era ficção mesmo. Ideia original, mas de difícil execução; outros escritores, convidados para participar na mesma coluna, acabaram desistindo. Continuei sozinho, e com o tempo, constatei que, atrás de muitas notícias de jornal, há uma história esperando para ser contada" (SCLIAR, 2007a, p. 251-252).
} 
Observam-se, em suas crônicas médicas, como no dizer de Iser (2013, p. 37), as "qualidades de manifestação que se evidenciam na seletividade do texto face a seus sistemas contextuais", identificando que a prática médica serviu de mote para sua literatura. Sobre a presença dessa prática em suas obras, Hanciau (2012, p. 114) afirma que "o texto exato, objetivo e cortante, Scliar certamente herdou dos prontuários médicos, que escreveu ao longo da vida e que, embora frios, trazem implícitas todas as dores do mundo. Os anos de Medicina ensinaram a diagnosticar a insondável criação literária”.

\section{O CINEMA NAS CRÔNICAS MÉdicas de MOACYr SCliar}

Na trajetória literária de Scliar, as crônicas não são secundárias. A inserção do escritor na imprensa é notória, tanto que Zilberman (2017, p. 5) observa que "além de duradoura, a participação de Scliar no jornalismo gaúcho, em especial em Zero Hora, foi intensa, resultando em mais de 5 mil crônicas". Antes do Zero Hora, escreve para o jornal universitário Bisturi, quando cursava Medicina, e, desde 1984, publica suas crônicas também em livro. Ao todo, foram 37 anos de produção contínua no gênero, e em parte dessa produção se verifica a sistemática tematização da medicina e o intertexto com o cinema na composição dos textos, muitas vezes de forma associada. Combinadas às três fases temáticas atribuídas à sua literatura - a cidade de Porto Alegre, a interface judaísmo-Brasil e a releitura de personagens bíblicas -, neste trabalho se propõe que, no tocante às crônicas, há outros dois temas significativos que marcam sua obra, as crônicas médicas: o tema da saúde e da prática da medicina, por um lado, e o intertexto com filmes e a produção cinematográfica, por outro.

Das entrevistas concedidas por Scliar, em poucas se indagou sobre seu interesse por cinema, mas, quando isso aconteceu, em entrevista concedida a Adriano Schwartz para a Folha de São Paulo, o escritor gaúcho respondeu:

Sou vidrado em cinema. Trata-se da grande arte narrativa do nosso tempo. O que um livro precisa de 400, 500 páginas para contar, o cinema conta em duas horas - isso é uma coisa que eu invejo profundamente. Eu gosto muito do Woody Allen judaico, não quando ele se mete a [Ingmar] Bergman. Gosto também do Stanley Kubrick, do Ettore Scola (SCLIAR, 1996, p. 5).

Nessa entrevista, realizada por ocasião do lançamento de seu livro Contos reunidos, Scliar aponta predileção pelo trabalho de conhecidos cineastas. ${ }^{3}$ Os filmes e séries que Scliar men-

\footnotetext{
${ }^{3} \mathrm{Na}$ crônica "Batalha final", publicada originalmente em 19 de fevereiro de 2000 e compilada no livro Território da emoção (2013), menciona um filme do diretor Martin Scorsese (1942), ampliando o leque de diretores com relação aos quais manifesta apreço. Outros diretores lembrados por Scliar são: a) Alfred Hitchcock, de Quando fala o coração (Spellbound), conforme se lê na crônica $O$ sono dos psicanalistas (SCLIAR, 2005, p. 67-69); b) Luis Garcia Berlanga, com o filme Tamanho Natural (cf. a crônica O amante da boneca, publicada no Zero Hora de 28 de fevereiro de 2010); c) Alan Resnais, diretor de $O$ ano passado em Marienbad (cf. Os segredos do spa) (SCLIAR, 2001, p. 14-16).
} 
ciona em seus textos, inclusive em seus romances, são quase sempre premiados: O jardineiro fiel (2006), por exemplo, entre outros prêmios, ganhou o Oscar e o Globo de Ouro.

Quanto à recorrência da associação temática, em A poesia das coisas simples, o cinema aparece brevemente atrelado à crônica médica Ler faz bem à saúde (alusão a um filme canadense) (SCLIAR, 2012, p. 73-74). O texto A mulher por trás do DNA (SCLIAR, 2012, p. 159-161) não é propriamente uma crônica que fornece conselhos sobre saúde: a referência à sétima arte consiste numa breve alusão ao fato de a vida da médica Rosalind Elsie Franklin ter sido convertida em filmes, conferindo a ela o reconhecimento devido. Ou seja, é uma crônica que relata bastidores da medicina. No Território da emoção, a alusão ao elemento cinematográfico pode ser vista no início de Médicos ou monstros? (SCLIAR, 2013, p. 72-74). Já Medicina e ficção menciona o filme Sherlock Holmes e as séries House e Grey's Anatomy, para mostrar como o cinema privilegia personagens médicos (SCLIAR, 2013, p. 33-34).

No conjunto da obra scliariana, uma das vertentes é a relação entre a literatura e a medicina. Em algumas crônicas, porém, há a incidência da inserção de outros elementos interartes, nesse caso cinematográfico/televisivo. Em Medicina e ficção, as duas séries que o escritor comenta estão ambientadas em hospitais e consultórios, e têm personagens médicos como protagonistas, ${ }^{4}$

Não são poucos os médicos que se transformaram em personagens, seja da literatura, seja do cinema, seja da TV, que gosta muito do hospital como cenário para seus dramas e ali coloca figuras como as de Ben Casey, do dr. Kildare, Marcus Welby, Meredith Grey (de Grey's Anatomy). Funciona: na Inglaterra, um curioso estudo mostrou que as pessoas conheciam mais o dr. Kildare, e mesmo o dr. Watson (amigo de Sherlock, ele é médico, mas não tem nenhuma habilidade especial, servindo mais como um interlocutor), do que médicos ingleses cujo trabalho beneficiou extraordinariamente a humanidade [...] (SCLIAR, 2013, p. 34). ${ }^{6}$

\footnotetext{
${ }^{4}$ Outra série televisiva relacionada a médicos é Doutor Kildare. Na crônica Erico, literatura e medicina, Scliar explica que o Doutor Kildare foi inspirado na idealização dos médicos: "Mesmo os ficcionistas têm dificuldades com seus personagens médicos. O erro mais frequente é o da idealização: o doutor-sacerdote, bonzinho, impecável. O expoente máximo desta linha é o edulcorado A. J. Cronin (aliás, médico) e dela derivaram as séries de TV tipo Doutor Kildare". Ressalta, também, que Erico Veríssimo - que era neto de médico e trabalhou numa farmácia - "soube transformar seus personagens médicos em seres humanos" (SCLIAR, 2012, p. 27). Nessa mesma crônica, há outra referência intermidiática e interartes, no caso com o teatro, pois Scliar escreve sobre a peça O dilema do médico (1911), de Bernard Shaw.

${ }^{5} \mathrm{O}$ hospital como cenário dos dramas médicos muitas vezes se apresenta vinculado a situações nas quais os profissionais da saúde precisam improvisar. Sobre esse tópico, no livro A face oculta, há a crônica A improvisação médica, na qual Scliar enumera algumas situações reais em que médicos "de carne e osso" combinam arrojo e imaginação a fim de salvar vidas. Desse modo, trabalhando nas longínquas Ilhas Salomão, o Dr. Alastair Coutts utilizou um chiclete para conseguir vedar o sangramento do crânio de uma senhora (SCLIAR, 2001b, p. 137-139).

${ }^{6}$ Cabe destaque, neste caso, à associação que Scliar faz entre Sherlock Holmes e o Dr. House. Essa mesma associação é trabalhada recentemente por Valéria Bussola Martins (2012), em um trabalho sobre as Versões literária e televisiva de Sherlock Holmes: um diálogo entre Comunicação, Educação e Letras.
} 
Medicina e ficção é uma das poucas crônicas em que Scliar menciona o cinema transversalmente no texto. Nesta, o cronista menciona personagens e séries médicas, tece comentários e reflexões sobre elas, o que não ocorre na maioria de suas demais crônicas médicas, nas quais a menção ao cinema/TV é mais sucinta e pontual. Nesses casos, como na crônica Imagens e emoções, discorre sobre a descoberta dos raios X, ilustrando sua importância, associando-a a um dos superpoderes de um herói do cinema: "Como enxergar o corpo por dentro? A primeira resposta veio no século XIX, com a descoberta dos raios X. Descoberta assombrosa, tanto que a visão de raios X era um dos poderes do Super-Homem" (SCLIAR, 2005, p. 65). Já na crônica Literatura como tratamento - compilada em Território da emoção-ele pondera que "no século XIX, eram os grandes romances - aqueles de Balzac, por exemplo - que ensinavam as pessoas a viver. Esse papel foi assumido pelo cinema e pela TV” (SCLIAR, 2013, p. 29).

O recurso ao intertexto com o cinema também se verifica em Indesejável efeito colateral, publicado pela primeira vez em outubro de 2005 e republicado em Território da emoção. Assim como em Medicina e ficção, logo no primeiro parágrafo, são mencionados o nome do filme e dos atores que desempenham cada papel. Nas crônicas, a primeira linha já traz o filme, seguido da observação de que se trata de um lançamento do cinema. "Está estrelando nos cinemas $O$ jardineiro fiel, dirigido pelo talentoso Fernando Meireles, com locações em Nairóbi, no Quênia, e no Sudão" (SCLIAR, 2013, p. 199). No primeiro parágrafo, acentua-se a relação entre literatura e medicina, visto que o filme é baseado no livro homônimo de John Le Carré, romancista britânico que escreveu sobre a tuberculose. O enredo é apresentado por Scliar: "uma trama envolvendo o teste de uma droga antituberculose pela indústria farmacêutica", chamando a atenção a que "pessoas pobres podem servir como cobaias humanas" para testes de novos medicamentos (SCLIAR, 2013, p. 199).

À semelhança de Indesejável efeito colateral, a crônica Batalha final é construída em três blocos, mas a menção ao cinema ocorre no início, desaparecendo em seguida. Publicado originalmente em fevereiro de 2000 , novamente principia a abordagem de um tema médico a partir de uma película: "O último filme de Martin Scorsese, Vivendo no limite (Bringing Out the Dead), gira em torno de um paramédico (Nicolas Cage) atormentado pela visão de uma aeromoça que ele não conseguiu salvar" (SCLIAR, 2013, p. 58). Depois de mencionar o filme, o diretor e o ator, dá início às reflexões sobre experiências dos profissionais da saúde com a morte:

Perder pacientes é o tormento dos paramédicos, e dos médicos, e dos enfermeiros, de todos enfim que lidam com a vida humana em seus instantes terminais. É o sombrio reverso de uma moeda cuja brilhante face nos mostra essas profissões arrancando pessoas à morte. Salvar vidas é "como se apaixonar", nas palavras de Joe Connelly, o paramédico autor do livro que originou o filme. É algo que dá aos profissionais a sensação de uma potência quase infinita (SCLIAR, 2013, p. 58). 
As ponderações sobre a condição humana e a saúde estão presentes, também, na crônica O TOC e suas incógnitas. Dividido em três segmentos, o texto traz, no segundo, uma lista de famosos que sofrem desse transtorno, como o ator Harrison Ford e o diretor Woody Allen, ilustrando manifestações desse transtorno em alguns deles: a atriz "Cameron Diaz lava as mãos várias vezes ao dia e só usa os cotovelos para abrir portas". Ao expor as dificuldades enfrentadas pelas celebridades, adverte que pessoas "comuns" podem também ser afetadas pelo Transtorno Obsessivo-Compulsivo (TOC), devendo procurar tratamento para esse mal (SCLIAR, 2013, p. 207). A crônica Os usos da obsessão, os usos da compulsão é igualmente dividida em três segmentos, sendo que a menção ao elemento cinematográfico aparece no primeiro e no terceiro blocos. No texto, mesclam-se particularidades da biografia do produtor de cinema Howard Hughes com eventos vivenciados por este quando afetado pelo TOC (SCLIAR, 2005, p. 91-93).

Outra crônica que se debruça sobre a história da medicina é Médicos ou monstros?, publicada originalmente em jornal em maio de 2005. Para adentrar nos feitos praticados por doutores simpatizantes do nazismo, Scliar associa uma produção fílmica à rememoração dos eventos narrados.

Há exatos sessenta anos terminava a Segunda Guerra Mundial, mas filmes como A queda, sobre os últimos e enlouquecidos dias de Adolf Hitler, mostram que o espectro do nazismo ainda nos acompanhará, e nos perturbará, durante muito tempo. A crueldade do regime hitlerista não foi só obra do ditador e de seus comparsas. Muitos outros participaram nos crimes de guerra, médicos inclusive (SCLIAR, 2013, p. 72).

No restante da crônica, não há menção ao filme. A importância conferida à temática judaica em sua obra, nesse caso, explica que vá "direto ao assunto", não se fixando em detalhes fílmicos, como ocorre em outras crônicas. Explicação que pode ser sustentada pela leitura de outras crônicas, nas quais retoma a trajetória de Hitler, como em A nostalgia de Hitler, publicado originalmente em outubro de 1977 e compilado por Regina Zilberman no livro A nossa frágil condição humana: crônicas judaicas. A nostalgia de Hitler é a primeira crônica desse livro (SCLIAR, 2017, p. 23-25); seguida pelo texto O sobrevivente, no qual se lê acerca das angústias de um supérstite do regime nazista (SCLIAR, 2017, p. 26-28).

Para elaborar o livro A nossa frágil condição humana (2017), Zilberman selecionou 68 crônicas escritas por Scliar para o jornal Zero Hora, no período de 1977 a 2010. Nesse livro, a temática medicina e o intertexto com obras fílmicas podem ser vistos nos seguintes textos: Mensagem de esperança, que enfatiza a relevância que tem a música, com seu componente humanista, para a sobrevivência física e mental do personagem principal; A nostalgia de Hitler, que inicia mencionando que o Führer reaparece glamourizado em livros e filmes, sendo que é possível cogitar comercializar qualquer coisa se valendo da figura de Hitler. Em A nostalgia 
de Hitler se lê: "o dr. Mengele, que trabalhava com cobaias humanas (injetava corantes nos olhos de crianças para torná-los azuis), bem que poderia abrir uma rede de clínicas para o tratamento dos indesejáveis" (SCLIAR, 2017, p. 25).

Publicada no Zero Hora de 4 de abril de 2004, Uma de 50 ou duas de 25? é outra das poucas crônicas médicas em que Scliar menciona o cinema transversalmente no texto. Essa obra também faz uso do cinema para fazer reflexões. A crônica evoca o enredo do filme Alguém tem que ceder, estrelado por Jack Nicholson, no personagem de um solteirão que, com uma namorada bem mais jovem do que ele, faz uso frequente de Viagra e, em decorrência dessa medicação, sofre um ataque cardíaco e acaba por apaixonar-se pela mãe da jovem namorada.

O filme faz com que apostemos nesse romance, que pode contrariar o evolucionismo, mas apela aos nossos sentimentos, e talvez até a uma certa lógica. Lógica que, diga-se de passagem, nem sempre regula a existência; como dizia o velho Pascal, o coração (e o genoma, podemos acrescentar) têm razões que a razão desconhece. Mas que tem beleza, a beleza das coisas lógicas. $O$ casal que envelhece junto não partilha apenas a cama; partilha segredos, gostos, manias. Como dizia um poema que li já não sei onde, "Nós dois somos uma multidão". E uma multidão é muito mais que duas, ou dois, jovens de 25 (SCLIAR, 2004, p. 4).

Na passagem, observa-se que Scliar se vale do cinema para refletir sobre situações corriqueiras e expressar intuições filosóficas concernentes aos "limites de uma racionalidade unicamente lógica e a respeito da apreensão de certos aspectos do mundo que não parecem ser captados por uma total exclusão do elemento afetivo" (CABRERA, 2006, p. 18). Outras crônicas nas quais Scliar menciona o cinema para fazer reflexões filosóficas são Nem Gatão, nem Bambi (23/04/2006) e Os graus da nossa separação (17/08/2003), ambas publicadas no Suplemento Donna do Jornal Zero Hora. No primeiro texto, o cronista rememora o filme Beleza americana para tecer reflexões médicas e existenciais sobre a crise da meia-idade em homens que arriscam uma volta à adolescência. No segundo, a partir da película estrelada por Donald Sutherland - Seis graus de separação - e do trabalho do psicólogo americano Stanley Milgram, Scliar pondera acerca das dificuldades de se comunicar nos diversos meios e níveis sociais.

\section{CoNSIDERAÇõES FINAIS}

Neste artigo, apresenta-se uma faceta ainda não estudada da produção do escritor, a saber, a recorrência da menção ao cinema em suas crônicas médicas e os modos como isso se dá. Para verificar essa faceta de sua obra, foi feito o levantamento de suas crônicas não publicadas em livros, o que constitui um aporte à fortuna crítica do escritor. Após um mapeamento inicial das distintas fases atribuídas à sua literatura, fez-se um escrutínio sobre a presença da crônica em sua trajetória, na qual se identificou sua assídua colaboração com um dos principais 
jornais do sul do país e, mais tarde, com outro de circulação nacional, explorando como esse contato perene com a lógica do trabalho jornalístico chega a influir em sua literatura.

As questões associadas às crônicas médicas que mencionam cinema e televisão são, no mais das vezes, aquelas mais difíceis de serem abordadas em público, das quais se fala a portas fechadas nos consultórios médicos ou com os amigos íntimos, por estarem relacionadas às mais diversas modalidades de estigmas, preconceitos e tabus religiosos arraigados na sociedade. Esses assuntos polêmicos, ou mais sensíveis, são tratados por Scliar de uma maneira leve, como que atenuando a gravidade atribuída socialmente a eles. Entre esses temas delicados, estão as terapias alternativas (Os segredos do spa, Como criar uma terapia alternativa) e as crendices que circundam as pessoas gêmeas (Fascínio múltiplo) e canhotas (O elogio dos canhotos), ou o tratamento para as questões da mente, como o psicanalítico (O sono dos psicanalistas e Terapia e fantasia). Fazem parte desse conjunto os temas aqueles relacionados ao sistema reprodutor e aos órgãos genitais, como a castração (Cirurgia radical), as dimensões do pênis (Pequeno? Nem tanto), a masturbação (O sorriso de Onan) e a circuncisão (A controvérsia da circuncisão). No que se refere aos hábitos polêmicos, estão os vícios, como o fumo (O primeiro cigarro a gente não esquece) e o alcoolismo (Confissão de um abstêmio). Os conflitos familiares comparecem em Casamento e saúde. Os estigmas suscitados pelos distúrbios mentais se evidenciam em O TOC e suas incógnitas e Nem sempre o psiquismo é o mais importante. O preconceito se manifesta na temática do racismo na medicina: em $O$ amante latino: raízes biológicas, Scliar relembra a opinião polêmica do cientista James Watson, que associa a cor da pele à intensidade do desejo sexual; e no uso de cobaias humanas em procedimentos médicos, como no texto Indesejável efeito colateral.

O câncer é outro tema sensível, um assunto considerado pesado, por ser uma doença temida. Scliar descontrai a abordagem mencionando o Godzilla, em O inimigo em nós, ao passo que, em O câncer como mensagem, o escritor explica o processo de propagação da enfermidade, lembrando uma cena do seriado de televisão Missão impossível, famoso na época. Esse aligeiramento diminui o sobressalto com o tópico da conversa - sim, o tom é muitas vezes o de uma conversa de sala de estar -, transformando a complexidade em algo mais acessível, como se lê nesse excerto:

O organismo tenta convencer a [célula] 'renegada' a desistir de seu propósito, às vezes até pela apoptose, que é uma espécie de suicídio celular, semelhante àquela mensagem do seriado de televisão Missão Impossivel, que vinha numa fita gravada e se autodestruía depois que era ouvida. Mas, por alguma razão, a célula pode prosseguir em sua trajetória (SCLIAR, 2001, p. 193-194).

Com relação ao modo, uma das maneiras de o cinema aparecer nas crônicas de Scliar é pela inserção pontual, ou seja, o escritor se vale de filmes, atores e personagens conhecidos para introduzir suas reflexões e elucidações sobre tópicos da medicina. Essa estratégia é 
condizente com a crônica ser um gênero mais enxuto e, portanto, demandar economia. Isso se verifica em Dentes e status, no qual Scliar sublinha o tema do recapeamento dental, ou seja, o emprego dos dentes como display social no meio artístico, ou menciona o enredo do filme Boca de Ouro, estrelado por Jece Valadão, e prossegue destacando a busca frenética pelo sorriso perfeito a que se submetem alguns atores e, por extensão, a sociedade. Em outras palavras, Scliar introduz uma situação, um hábito, a partir do divulgado sobre a vida dos olimpianos (MORIN, 2011), algumas vezes de Hollywood, personagens que dispensam apresentação ou caracterização. Da mesma forma, em O TOC e suas incógnitas, Scliar elenca atores famosos, a partir dos quais exemplifica alguns tipos do transtorno vivenciado por eles, associando, paradoxalmente, características passíveis de estigma a celebridades do cinema e da televisão, admiradas pelo grande público, tensionando assim o preconceito e a sua vulgar associação aos párias, aos "esquisitos".

Ainda percorrendo o eixo da inserção pontual do cinema na crônica, nota-se que, em O primeiro cigarro a gente não esquece, Scliar problematiza a temática do fumo e é por meio da menção à famosa atriz Ingrid Bergman que o escritor acrescenta mais algumas de suas reflexões. De modo semelhante, em Como criar uma terapia alternativa, Scliar apresenta seis táticas para se criar uma terapia alternativa, e no quinto segredo menciona a atriz Cláudia Raia e comportamentos de atores de televisão, sugerindo uma explicação para citar atores e filmes de sucesso: eles têm apelo de público, chamam a atenção do leitor. Nesse caso, a atriz aparece como um personagem que dispensa descrição, pois tem seu estilo de vida e gostos divulgados para o grande público. Uma segunda classe de inserção pontual é pela apresentação do tema, como no caso da castração, introduzido na crônica Cirurgia radical por meio da reminiscência ao filme Farinelli - Il Castrato, película que conta a trajetória de um cantor castrado do século XVIII, evocando uma questão curiosa e sombria.

O segundo modo pelo qual o cinema comparece na obra do cronista sulino é pela referência intermidiática. Em Médicos ou monstros?, o escritor cita frequentemente elementos audiovisuais, televisivos e cinematográficos, principalmente, e constrói sua argumentação a partir de analogias com o tema central dessas obras ou, com mais frequência, com características e atributos de seus personagens ou das situações apresentadas pelos enredos. A relação é, principalmente, de citação, na qual menciona filmes, trazendo-os prevalentemente desde seus aspectos conteudísticos: temas, personagens e situações. Esse tipo de citação traz consigo pelo menos dois tipos de resultados. O primeiro, promove as obras citadas, chamando a atenção do público do jornal para a oferta cultural do momento, apontando aspectos de interesse que podem justificar a busca por elas nas salas de cinema ou na televisão. Nesse caso, vale ressaltar a mídia de publicação da crônica, o jornal diário, e por isso associada aos temas da atualidade e aos demais cadernos e editorias do periódico.

O segundo desdobramento da referência intermidiática é voltado para a relação entre leitor e tema tratado, pois, com frequência, sua linha de argumentação promove o 
esclarecimento sobre assuntos associados a preconceitos, ou vetados pela religião ou pelo costume de ter um tratamento aberto e científico, por vieses não dogmáticos e sim mundanos, secularizados. Esse segundo resultado traz à tona um traço marcante em suas crônicas médicas: seu teor informativo, pois amiúde, em meio à "conversa”, o escritor tipifica, qualifica e explica aspectos dos tópicos que introduz. A referência intermidiática também se notabiliza em Erico, literatura e medicina, texto no qual inicialmente Scliar explica como o cinema privilegia personagens médicos, para, em seguida, fazer menção à adaptação de Olhai os lírios do campo, livro de Erico Veríssimo, para a TV. Aqui, o percurso é da literatura para a televisão, e a referência midiática é dupla: o livro e a novela. E nisso tratando de representação dos médicos, da categoria profissional, do interesse que desperta e de como estes são representados por vezes de forma idealizada.

Cabe ressaltar, a título de fechamento, que, na trajetória literária de Scliar, as crônicas não são produções secundárias ou esporádicas. Destaca-se, adicionalmente, que muito dessa prolífica produção cronística foi marcada pela recorrência sistemática à tematização do cinema e da medicina, muitas vezes de forma associada. Verificou-se, nesse sentido, a importância dessa associação, numa forma de propor questões complexas por um viés do cotidiano e ao rés-do-chão (CANDIDO, 1992), acentuando sua vinculação ao jornal, e em tom de conversa, na qual se entremeiam informações e elucidações nos exemplos e comentários sobre as situações e tópicos introduzidos. Identificou-se que a mídia cinema e as obras fílmicas são usadas nas crônicas como recurso composicional, seja para exemplificar questões complexas a partir do sucedido em filmes de ampla bilheteria, atenuando a gravidade socialmente atribuída a elas, ou com fatos notórios divulgados sobre a vida dos olimpianos do cinema, seja para desenvolver ou ilustrar, de modo concreto, reflexões abstratas e expressar intuições filosóficas.

\section{REFERÊNCIAS}

CABRERA, Julio. O cinema pensa: uma introdução à filosofia através dos filmes. Tradução de Ryta Vinagre. Rio de Janeiro: Rocco, 2006.

CANDIDO, Antonio. A vida ao rés-do-chão. In: CANDIDO et al. A crônica. O gênero, sua fixação e suas transformações no Brasil. Campinas: UNICAMP; Rio de Janeiro: Fundação Casa de Rui Barbosa, 1992, p.13-22.

FISCHER, Luís Augusto. A crônica de Moacyr Scliar: Luís Augusto Fischer entrevista Moacyr Scliar. In: WebMosaica: revista do Instituto Cultural Judaico Marc Chagall. v. 3, n. 1, jan-jun 2011. p. 101-102. Disponível em: https://seer.ufrgs.br/webmosaica/article/view/22368/13024. Acesso em: 1 out. 2019.

FISCHER, Luís Augusto (Org.). Moacyr Scliar. São Paulo: Global, 2004. (Coleção Melhores Crônicas / Direção Edla van Steen). 
GENETTE, Gérard. Palimpsestos: a literatura de segunda mão. Extratos traduzidos do francês por Luciene Guimarães e Maria Antônia Ramos Coutinho. Belo Horizonte: Faculdade de Letras, 2006. GOMES, Márcia. O intertexto midiático: ficção seriada televisiva e adaptação de obras literárias. As ideias no fluxo das mídias. Conexão (UCS), v. 08, p. 92-108, 2009.

GRANJA, Lúcia. Crônica. Chronique. Crónica. In: Revista da Anpoll n. 38, p. 86-100, Florianópolis, Jan./Jun. 2015.

GUIMARÃES, Lealis Conceição. Do fato ao texto literário: as saborosas crônicas de Moacyr Scliar. Dissertação de Mestrado - Faculdade de Ciências e Letras de Assis - Universidade Estadual Paulista. Assis, 1999. 178 p.

HANCIAU, Nubia. Moacyr Scliar e a crônica. In: BERND, Zilá; MOREIRA, Maria Eunice; MELLO, Ana Maria Lisboa de (Org.). Tributo a Moacyr Scliar. Porto Alegre, RS: EDIPUCRS, 2012. p. 111-125.

ISER, Wolfgang. O fictício e o imaginário. Perspectivas de uma Antropologia Literária. Rio de Janeiro, Ed. UERJ, 2013.

MARTÍN BARBERO, Jesús. De los Medios a las Mediaciones. Comunicación, Cultura y Hegemonía. México: Ediciones G.Gili, 1987.

MORIN, Edgar. Cultura de massas no século XX: o espírito do tempo, v. 1: neurose. 10. ed. Rio de Janeiro, RJ: Forense Universitária, 2011.

RAJEWSKY, Irina. Intermidialidade, Intertextualidade e "Remediação": uma perspectiva literária sobre a intermidialidade. In: DINIZ, T.; VIEIRA, A. (Org.). Intermidialidade e Estudos Interartes: desafios da arte contemporânea. Belo Horizonte: FALE/UFMG, 2012, p. 15-45.

SCHWARTZ, Adriano. A literatura do conflito: Moacyr Scliar fala sobre seus "Contos Reunidos". São Paulo: Folha de São Paulo, 4 fev. 1996, p. 5.

SCLIAR, Moacyr. Entrevista. Disponível em: http://www.jornalolince.com.br/2008/nov/ entrevista/scliar.php. Acesso em: 8 jul. 2014.

SCLIAR, Moacyr. Falar com Deus? Só se for com ligação a cobrar. Disponível em: http:// helenamacspubofwords.blogspot.com/2011_02_07_archive.html?view=classic. Acesso em: 13 jun. 2019.

SCLIAR, Moacyr. A massagista japonesa. Porto Alegre: L\&PM, 1984. (Coleção RBS)

SCLIAR, Moacyr. A face oculta: inusitadas e reveladoras histórias da medicina. Porto Alegre: Artes e Ofícios, 2001b.

SCLIAR, Moacyr. A língua de três pontas: crônicas e citações sobre a arte de falar mal. Porto Alegre: Artes e ofícios, 2001.

SCLIAR, Moacyr. A linguagem médica. São Paulo: Publifolha, 2002. (Coleção Folha explica). 
SCLIAR, Moacyr. A mulher que escreveu a Bíblia. São Paulo: Companhia das Letras, 2007. (Companhia de Bolso).

SCLIAR, Moacyr. A poesia das coisas simples: crônicas. Organização e prefácio de Regina Zilberman. São Paulo: Companhia das Letras, 2012.

SCLIAR, Moacyr. A nossa frágil condição humana: crônicas judaicas. Organização e prefácio de Regina Zilberman. São Paulo: Companhia das Letras, 2017.

SCLIAR, Moacyr. Dicionário do viajante insólito. Porto Alegre: L\&PM, 2011. (Coleção L\&PM POCKET, v. 329).

SCLIAR, Moacyr. Do jeito que nós vivemos. Belo Horizonte: Editora Leitura, 2007.

SCLIAR, Moacyr. Histórias que os jornais não contam. Rio de Janeiro: Agir, 2009.

SCLIAR, Moacyr. Histórias de Porto Alegre. Porto Alegre: L\&PM, 2005.

SCLIAR, Moacyr. Manual da paixão solitária. São Paulo: Companhia das Letras, 2008.

SCLIAR, Moacyr. Meu filho, o doutor: medicina e judaísmo na história, na literatura e no humor. Porto Alegre: Artmed Editora, 2001c.

SCLIAR, Moacyr. Minha mãe não dorme enquanto eu não chegar. 2. ed. Porto Alegre: L\&PM, 1996. (Coleção A leitura é uma aventura).

SCLIAR, Moacyr. Nem Gatão, nem Bambi. Disponível em: http://www.moacyrscliar.com/ cronicas/nem-gatao-nem-bambi/. Acesso em: 16 ago. 2020.

SCLIAR, Moacyr. O amante da boneca. Disponível em: https:/gauchazh.clicrbs.com.br/donna/ noticia/2010/02/moacyr-scliar-o-amante-da-boneca-cjpms1x650ofevtcnn173alpa.html. Acesso em: 7 ago. 2020.

SCLIAR, Moacyr. Os graus da nossa separação. Disponível em: http://www.moacyrscliar.com/ arquivos/cronicas/os-graus-da-nossa-separacao.pdf. Acesso em: 16 ago. 2020.

SCLIAR, Moacyr. O imaginário cotidiano. 2. ed. São Paulo: Global, 2002.

SCLIAR, Moacyr. O olhar médico: crônicas de medicina e saúde. São Paulo: Editora Ágora, 2005. SCLIAR, Moacyr. O texto, ou: a vida: uma trajetória literária. Rio de Janeiro: Bertrand Brasil, 2007 .

SCLIAR, Moacyr. Os vendilhões do templo. São Paulo: Companhia das Letras, 2006.

SCLIAR, Moacyr et al. Pátria estranha. São Paulo: Nova Alexandria, 2002.

SCLIAR, Moacyr. Porto de histórias: mistérios e crepúsculo de Porto Alegre. Rio de Janeiro: Record, 2000. (Coleção Metrópoles).

SCLIAR, Moacyr. Território da emoção: crônicas de medicina e saúde. Organização e prefácio de Regina Zilberman. São Paulo: Companhia das Letras, 2013. 
SCLIAR, Moacyr. Um país chamado infância. Porto Alegre: Sulina, 1989.

SCLIAR, Moacyr. Uma de 50 ou duas de 25? Disponível em: http://www.moacyrscliar.com/ cronicas/uma-de-50-ou-duas-de-25/. Acesso em: 7 ago. 2020.

SZKLO, Gilda Salem. O bom fim do shtetl: Moacyr Scliar. São Paulo: Perspectiva, 1990. (Debates; V. 231).

WALDMAN, Berta. Entre passos e rastros: presença judaica na literatura brasileira contemporânea. São Paulo: Perspectiva; FAPESP: Associação Universitária de Cultura Judaica, 2003. (Estudos; 191).

ZILBERMAN, Regina. Do Bom Fim para o mundo: entrevista com Moacyr Scliar. In: WebMosaica: revista do Instituto Cultural Judaico Marc Chagall.v. 1, n. 2, jul.-dez. 2009. p. 116-120. Disponível em: http://www.google.com.br/url?sa=t\&rct=j\&q=\&esrc=s\&source=web\&cd=1\&ved=oCCoQ FjAA\&url=http\%3A\%2F\%2Fwww.seer.ufrgs.br\%2Fwebmosaica\%2Farticle\%2Fdownload\%2F11 987\%2F7128\&ei=uwt7U63bG8SBqgbEp4H4CA\&usg=AFQjCNE68PxXEbR5VSKFGeWVYGkBa OKliQ. Acesso em: 20 maio 2014.

ZILBERMAN, Regina. Cronista e leitor. In: SCLIAR, Moacyr. A poesia das coisas simples: crônicas. São Paulo: Companhia das Letras, 2012. p. 9-17.

ZILBERMAN, Regina. O olhar mágico de Moacyr Scliar. In: SCLIAR, Moacyr. A nossa frágil condição humana: crônicas judaicas. São Paulo: Companhia das Letras, 2017. p. 1-29.

Recebido para publicação em: 1 set. 2020. Aceito para publicação em: 19 jan. 2021. 